Katerina Pojkarova - Dalibor Gottwald*

\title{
DO AIR PASSENGERS DECIDE RATIONALLY? CASE STUDY OF TRAVELLERS ON ROUTE PRAGUE-LONDON
}

Decision-making is an integral part of every human's life, both personal and professional, and today's highly globalized world brings many different factors that affect the decision-making process. General economic theory of utility is grounded in the assumption that people make decisions rationally. Recently, however, its limits have been challenged by both scientific and professional public - the theory of rational choice acknowledges only a limited number of factors that influence the decision-making. The aim of the present article is to discover whether the current debate can be applicable to decision-making processes of flight passengers in a case study of travelers on route from Prague to London. The article presents results of a primary research carried out by authors in 2018. The survey set to explore validity of choice theory in the sector of logistics, in particular in decision-making processes of passengers who buy flight ticket on route Prague - London. At the base of result it can be confirmed that the classical theory of rational choice in economical perspective has been proven false. When people's behavior, as a result of their decision making, serves as a basis for future predictions of development in a given area, it is essential to take into account other, usually hidden factors, which also affect the decision-making process.

Keywords: rational choice theory, passengers, air transport, decision making, irrational decisions

\section{Introduction and background}

Rational choice theory, a theory explaining human behavior in decision-making processes related to economic issues, has until only recently been a central paradigm in economics. The theory views an individual as homo economicus who makes choices in a rational manner, seeking to minimize loss and maximize gain, while being systematically economical and taking into account various aspects at the same time [1]. This approach has been used in economics and the last decades saw its outreach into other areas, most notably sociology and political sciences [2, 3]. Implementation of the theory into other areas has resulted in a debate over its validity and the increasingly globalized environment gave way to criticism of its purely economic interpretations. The main vein of criticism is its limitations in terms of number of factors that the theory acknowledges. Many specialists believe that humans are influenced by a wide range of hidden irrational factors that stem from early life stages, including emotions, societal norms and prejudices, and together with a wide array of marketing activities influence the decisionmaking processes $[4,5]$. Severe income polarity is one of the proofs of human irrationality. If people behaved rationally, the following statement would be true: The more an employee earns, the more motivated he or she is to deliver a better work performance. Validity of this statement has been verified in a number of experiments. One of them investigated the effect of small, medium and high bonuses on intellectual performance of employees. Results have shown that groups that have been promised the highest bonus performed the worst [6]. This result can be explained using Kahneman and Tversky prospect theory, especially in terms of a loss aversion. The fear of losing a high yearly bonus, which the employees count on throughout the year, is more stressful than motivating for their intellectual performance [7]. Such experiments show that it is essential to know relationships between remuneration, motivation, stress and performance. Generally, it can be said that humans are not rational, especially when in stressful situations or under pressure. In this way, a certain deficiency of the classical theory of rational choice can be seen $[6,8,9]$. There are several articles published on this topic, where irrational behavior is tested in different areas such as eating habits, tourism, politics or psychology [10-13]. The aim of this article is to verify if people are rational in their decision-making. The article presents results of a primary research carried out by authors in 2018. The survey is set to explore validity of choice theory in the sector of logistics, in particular in decisionmaking processes of passengers who buy flight ticket on route Prague - London.

\section{Methodology}

Data used in this article were gathered in an online questionnaire survey, whose respondents were air passengers.

\subsection{Subject of survey}

The questionnaire was administered through Facebook pages of a flight tickets seller Happyfly.cz and through selected Facebook pages that deal with travelling or provide tips on cheap flight tickets, namely: Cestovani a turistika (Travel and tourism); Cestovani - zabava, inspirace i pouceni (Travel - entertainment, inspiration and teaching); Cestovani po svete s detmi (Traveling around the world with children); Vylety a cestovani (Trips and travelling); Milujeme letadla - letani (cestovani) (We love planes

\footnotetext{
* Katerina Pojkarova, Dalibor Gottwald

Faculty of Transport Engineering, University of Pardubice, Czech Republic

Email: dalibor.gottwald@upce.cz
} 
- flying (travelling)); Nejvyhodnejsi cestovani (The most benefit travelling); Akcni letenky a cestovani po svete (Action trips and travel around the world); Individualni cestovani (Individual travel); Londyn (London); Milujeme cestovani (We love travelling); Levnocestovani. $c z$ (Cheaptravelling.cz); Cestovadlo (Cestovadlo). The questionnaire was open from June 25, 2018 through August 4, 2018. Altogether, 109 responses were yielded and data were then analyzed.

\subsection{Survey design}

The questionnaire was designed in such a way that it made possible to verify or falsify the theory of rational choice. It comprised three parts where respondents were gradually provided with information on flights, duration of travel and its cost, and a general identification part. The first part presented respondents with the following Model situation 1: "You are planning a longweekend trip to London - a regular sightseeing trip with a visit to Westminster Abbey, Tower Bridge, Buckingham Palace etc. You want to leave from Prague and the following ten flights are available. Put them into order based on your preferences (choose at least five flights)." Respondents could choose from ten flights. In this model situation, they were given information about the air company, departure and arrival times, destination airport, flight ticket price and flight duration. After selecting at least five flights, they were asked to answer the following question: "Which criterion was the most important when choosing the order of flights?". They could choose from air company, departure and arrival times, location of the destination airport, flight ticket price, flight duration and other. In the case that they selected other, respondents were asked to specify their answer.

In the second part of the questionnaire, respondents were presented with Model situation 2, which in addition to information provided in Model situation 1 also included information on duration of journey from London airports to London city center and overall time spent travelling (the most convenient option in terms of overall time spent travelling, i.e. the sum of flight duration and duration of journey from the airport to the center, was highlighted). After selecting the preferred five flights, they were again asked to select the most important criterion for their choice. This time, the selection of criteria also included duration of journey from the airport to the city center and overall time spent travelling.

The third part of the questionnaire used Model situation 3, which, in addition to the information provided in the two preceding model situations, included information on price of public transport tickets (from London airports to London city center) and total cost of transport, i.e. the sum of the flight ticket price and the price of public transport tickets (the cheapest option was highlighted). Again, respondents were asked to select at least five flights and then select the most important criterion for their choice. This time, the selection of criteria also included options price of public transport tickets (from London airports to London city center) and total cost of transport.

The last part of the questionnaire comprised general identification questions. Respondents were asked to answer these questions: "What is your experience with air travel?" (area 1), "What is your experience with air travel to London?" (area 2), "What is your experience with arranging trips such as a long weekend abroad, regular trip to cities abroad etc. with the use of air travel?" I (area 3) and provide information on their sex (area 4) and highest achieved education (area 5).

Data gathered in the survey were used to verify the validity of rational choice theory in buying flight tickets. The question related to experience is highly important - it is assumed that experienced respondents will take into account all additional costs, such as price of public transport tickets, or the time spent travelling to the city center from farther airports. Respondents were grouped by areas in the identification analysis and Pearson's chi-squared test was used to verify their consistency in selection of preferred flights in Model situations 1 through 3.

$x^{2}=\sum_{i=1}^{n} \frac{\left(O_{i}-E_{i}\right)^{2}}{E_{i}}=N \sum_{i=1}^{n} \frac{\left(O_{i} / N-p_{i}\right)^{2}}{p_{i}}$,

$x^{2}$ Pearson's cumulative test statistic, which asymptotically approaches a $x^{2}$ distribution,

$O_{i}$ the number of observations of type $i$,

$N$ total number of observations,

$E_{i}$ the expected (theoretical) count of type $i$, asserted by the null hypothesis that the fraction of type $i$ in the population is $p_{i}$, $n$ the number of cells in the table.

\section{Results}

Results of the survey show that when only basic information was provided (air company, departure and arrival times, destination airport, flight ticket price and flight duration, i.e. Model situation $1)$, most respondents $(32 \%)$ selected as their first preferred the Ryanair flight at 6:40 AM, which was the first flight of the day and one of the three most expensive. Only a few respondents preferred late evening or night flights. Departure and arrival times was among the most common criteria for their choice - $53.2 \%$ of respondents selected it as the most important one, while only $16.5 \%$ decided by the price.

Figure 1 shows that when given additional information (duration of journey from London airports to London city center and overall time spent travelling, i.e. Model situation 2), respondents did not change their answers significantly. Again, the most preferred flight was the Ryanair flight at 6:40 AM (34 \%). No respondents chose late evening or night flights as the most preferred ones.

Departure and arrival times was again the most important criterion (38.5\%), followed by flight ticket price (18.35\%). However, $11.93 \%$ of respondents stated that the main criterion was duration of journey from London airports to London city center. This is quite surprising since the preceding section has shown that flight duration, also a time criterion, was not deemed important by respondents.

Model situation 3 (see Figure 2) with additional information on price of public transport tickets (from London airports to London city center) and total cost of transport brought significant changes. This time, $41 \%$ of respondents chose the British Airways flight at

1 "Arranging" is here used to mean buying tickets, finding out about local public transport costs in target destination etc. 
Model situation 2

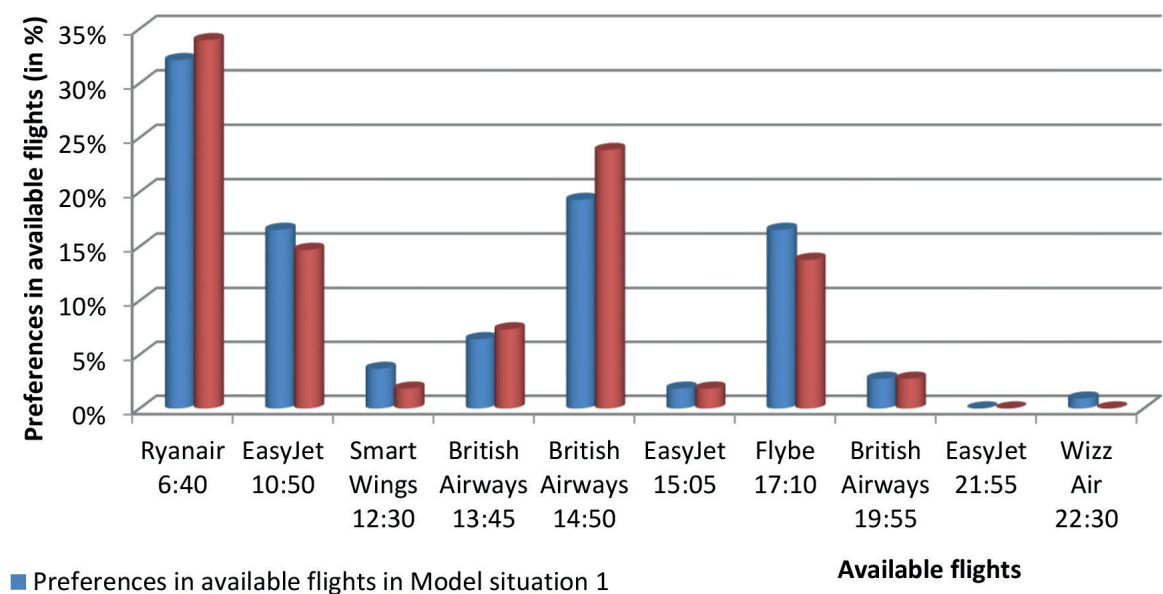

- Preferences in available flights when provided with information on duration of journey from London airports to London city center and overall time spent travelling (Model situation 2)

Figure 1 Model situation 2

\section{Model situation 3}

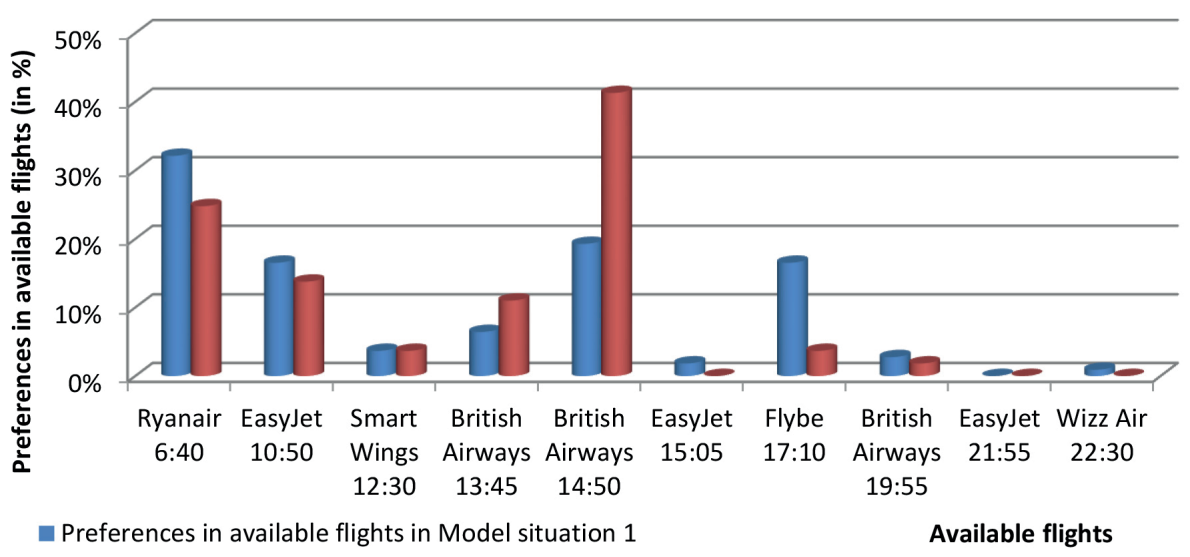

- Preferences in available flights when provided with information on price of public transport tickets (from London airports to London city center) and total cost of transport (Model situation 3 )

Figure 2 Model situation 3

2:50 PM as the best one ${ }^{2}$, while the Ryanair flight at 6:40 AM was chosen by $25 \%$ only.

In Model situation 3, the main criterion was total cost of transport for $42.2 \%$ while departure and arrival times was selected by only $26.6 \%$, a half less than in the preceding Model situation. One third of respondents stated the same main criterion in all the three model situations - it was departure and arrival times for $75 \%$ of them, while the rest opted for air company or flight ticket price.

In Model situation 1, 25\% of respondents selected departure and arrival times as the most important criterion. This gradually changed with adding further information until total cost of transport became the most important criterion. It follows that respondents changed their decisions when presented with additional information, which is not very surprising. What is surprising is the fact that the preferred order of flights in Model situations does not comply with the theory of rational choice

2 The overall cost of transport from Prague to London city center is the lowest with the British Airways flight at 2:50 PM.
- respondents did not always choose the option that would minimize their loss and maximize their gain. Respondents were inconsistent in their choice of preferred flights, as well as in criteria that guided their choice.

Comparing experienced and less experienced respondents also brings interesting data. Experienced travelers are those who answered the question "What is your experience with arranging trips such as a long weekend abroad, regular trip to cities abroad etc. with the use of air travel?"3 that they have arranged such a trip at least four or more times. Non-experienced are those who answered they have no such experience. Figures 3 and 4 show differences in changes of preferred flights in experienced and nonexperienced respondents in Model situation 3.

Figures 3 and 4 show that non-experienced respondents show greater differences in decisions, but visible changes were made also by more experienced travelers.

3 "Arranging" is here used to mean buying tickets, finding out about local public transport costs in target destination etc. 


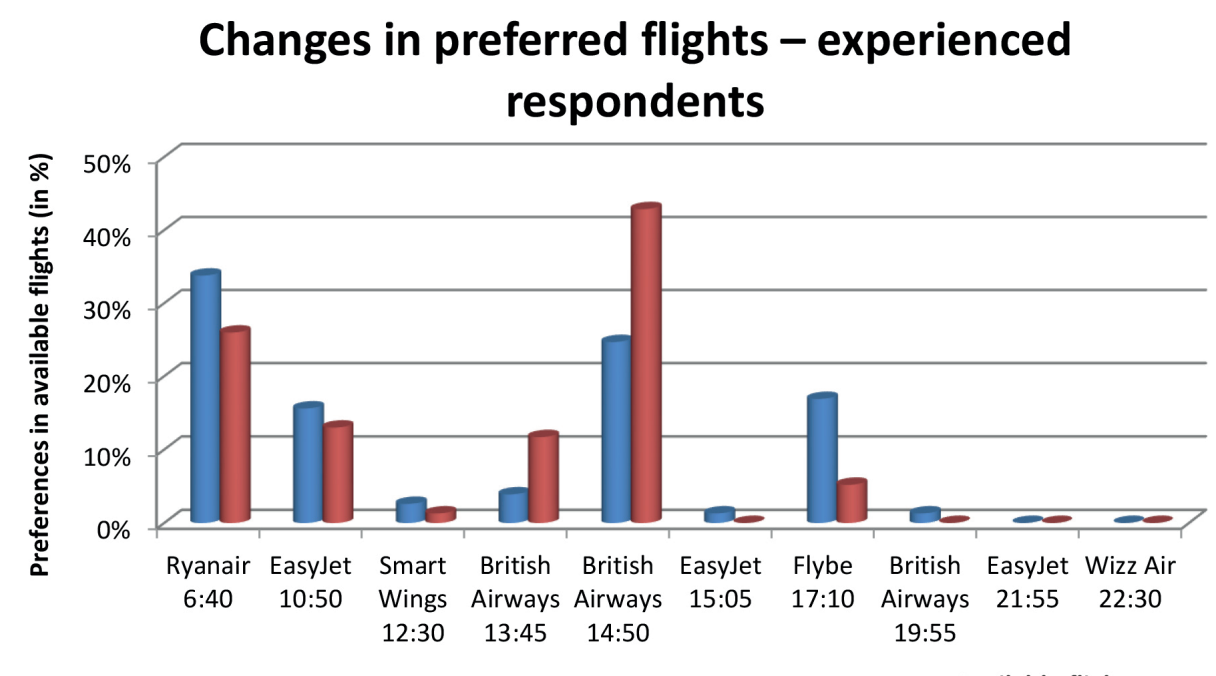

- Preferences in available flights in Model situation 1

Available flights

- Preferences in available flights when provided with information on price of public transport tickets (from London airports to London city center) and total cost of transport (Model situation 3)

Figure 3 Changes in preferred flights - experienced respondents

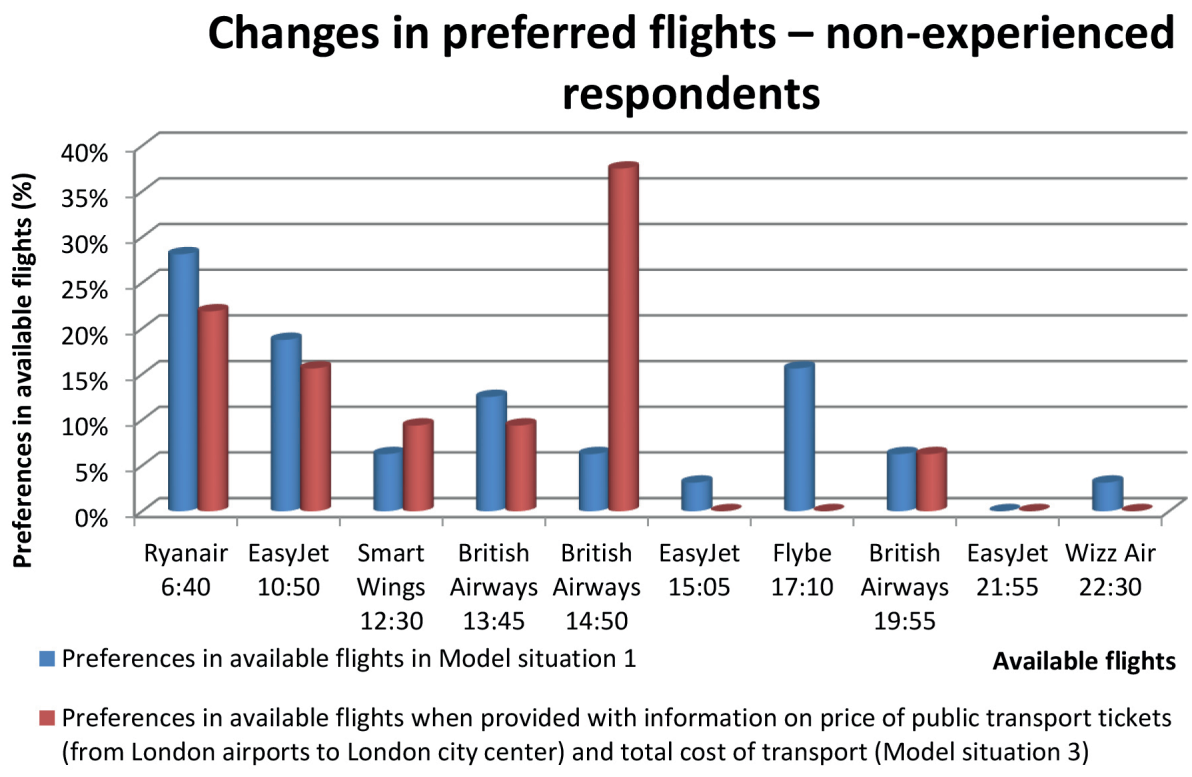

Figure 4 Changes in preferred flights - non-experienced respondents

The Pearson's chi-squared test was used to discover whether groups of respondents categorized by areas in identification questions were consistent in their choices of preferred flights in Model situations 1 through 3. Table 1 shows results of the Pearson's chi-squared test.

With statistical error of $5 \%$, it can be concluded that no group of respondents was consistent in their choices of preferred flights in Model situations 1 through 3. It becomes evident that not even experienced travelers decided rationally. To prove the rational choice theory right, respondents would have to select the same criterion in all model situations, always bearing in mind their economical perspective and always selecting the lowest price over other factors.

\section{Discussion and conclusions}

The present article examined rationality when buying flight tickets, in particular in travelers on route Prague - London. This is a very current topic since many authors have pointed out the limits of the rational choice theory in its classical economical perspective. People are daily confronted with an immense number of factors that may influence their decisions and it becomes virtually impossible to realize their influence on one's decisions. The probability that the final decision will always be in accordance with the assumption that all the decisions are made to minimize one's loss and maximize his or her gain, is very small.

The preceding section has shown results of authors' survey whose results clearly confirm that passengers do not behave rationally in presented Model situations. Consistency, or 
Table 1 Results of the Pearson's chi-squared test

\begin{tabular}{cccc}
\hline Area of identification analysis & $x^{2}$ & p-value & $\begin{array}{c}\text { Statistically significant at an alpha } \\
\text { level of 0.05 }\end{array}$ \\
\hline Experience with air travel (area 1) & 0.183 & 0.669 & $\mathrm{NO}$ \\
Experience with travelling to London (area 2) & 0.491 & 0.484 & $\mathrm{NO}$ \\
Experience with arranging trips abroad (area 3) & 0.410 & 0.522 & $\mathrm{NO}$ \\
Sex (area 4) & 1.402 & 0.236 & 0.522 \\
Achieved education (area 5) & 0.417 & $\mathrm{NO}$ \\
\hline
\end{tabular}

rationality, in decision making was not found even in passengers who are, according to their own words, experienced in buying tickets. The difference in consistency has not been confirmed from any investigated perspective: gender, education attained, experience with air travel, experience with travelling to London (see Table 1).

If the rational choice theory was to be confirmed, respondents would have to select one and the same criterion in all the model situations. However, respondents were influenced by the gradually provided information on duration of journey from the airport to the city center, overall time spent travelling, cost of public transport tickets or total cost of transport.

Validity of rational choice theory would be confirmed even if respondents chose different criteria in every model situation because for example Model situation 1 did not include information on overall cost. In such a case they would have to select a criterion that would minimize their loss and maximize their gain to prove the theory right. However, not even that happened in the survey - respondents were inconsistent in their choice of criteria and most of them also in the choice of one criterion in each model situation. Detailed analysis of their answers showed that although respondents stated their decision depended mainly on price, they did not opt for flights with the lowest price in their preferred flights.

To conclude, it can be confirmed that the classical theory of rational choice in economical perspective has been proven false. When people's behavior, as a result of their decision making, serves as a basis for future predictions of development in a given area, it is essential to take into account other, usually hidden factors, which also affect the decision-making process.

\section{References}

[1] KAHNEMAN, D. Thinking, fast and slow. New York, NY, US: Farrar, Straus and Giroux, 2011. ISBN 978-0-3742-7563-1.

[2] SWEDBORG, R. Economic and sociology. Princeton: Princeton University Press, 1990. ISBN 9780691003764.

[3] GREEN, D. P., SHAPIRO, I. Pathologies of rational choice theory: A critique of applications in political science. New Haven: Yale University Press, 1996. ISBN 0-300-06636-8.

[4] ARIELY, D. Predictably irrational: The hidden forces that shape our decisions. New York: Harper Collins, 2009. ISBN 978-0-06135323-9.

[5] KISER, E., HECHTER, M. The debate on historical sociology: Rational choice theory and its critics. American Journal of Sociology [online]. 1998, 104(3), 785-816. ISSN 0002-9602/eISSN 1537-5390. Available from: https://doi.org/10.1086/210086

[6] ARIELY, D. The upside of irrationality: The unexpected benefits of defying logic. New York: Perennial, 2011. ISBN 978-0-06-199504-0.

[7] KAHNEMAN, D., TVERSKY, A. Prospect Theory: An analysis of decision under risk. Econometrica [online]. 1979, 47(2), p. 263292. ISSN 00129682/eISSN 14680262. Available from: https://doi.org/10.2307/1914185

[8] INFANTE, G., LECOUTEUX, G., SUGDEN, R. Preference purification and the inner rational agent: a critique of the conventional wisdom of behavioral welfare economics. Journal of economic methodology [online]. 2016, 23(1), p. 1-25. ISSN 1350-178X/eISSN 1469-9427. Available from: https://doi.org/10.1080/1350178X.2015.1070527

[9] VANBERG, V. J. Rationality and rules: Behavioral foundations and policy implications. History of Economic Ideas [online]. 2016, 24(3), p. 95-113. ISSN 11228792/eISSN 17242169. Available from: https://doi.org/10.19272/201606103005

[10] WANG, J., SHEN, M., GAO, Z. Research on the irrational behavior of consumers' safe consumption and its influencing factors. International Journal of Environmental Research and Public Health [online]. 2018, 15(12), 2764. ISSN 1661-7827/eISSN 1660-4601. Available from: https://doi.org/10.3390/ijerph15122764

[11] PARK, S., NICOLAU, J. L. If you, tourist, behave irrationally, I'll find you! Tourism Management [online]. 2018, 69, p. 424-439. ISSN 0261-5177/eISSN 1879-3193. Available from: https://doi.org/10.1016/j.tourman.2018.06.017

[12] AALDERING, L. Research on the irrational behavior of consumers' safe consumption and its influencing factors. Electoral studies [online]. 2018, 54, p. 269-288. ISSN 0261-3794/ISSN-L 0261-3794. Available from: https://doi.org/10.1016/j.electstud.2018.04.010

[13] STAMOVLASIS, D., VAIOPOULOU, J. The role of dysfunctional myths in a decision-making process under bounded rationality: A complex dynamical systems perspective. Nonlinear Dynamics, Psychology, and Life Sciences [online]. 2017, 21(3), p. 267-288. ISSN 1090-0578/ISSN-L 1090-0578. 